\title{
THE INTERFACE FRICTION
}

\section{IN THE FRICTION-TYPE BOLTED JOINT OF STEEL TRUSS BRIDGE: CASE STUDY}

\author{
GAOXIN WANG ${ }^{1 *}$, YOULIANG DING ${ }^{2}$ \\ ${ }^{1}$ State Key Laboratory for Geomechanics and Deep Underground Engineering, \\ China University of Mining and Technology, \\ Xuzhou, China \\ ${ }^{2}$ The Key Laboratory of Concrete and Prestressed Concrete Structures \\ of Ministry of Education, Southeast University, Nanjing, China
}

Received 19 July 2018; accepted 16 July 2019

\begin{abstract}
The friction-type bolted joint transfers the internal forces in the structural members by interface friction, but noticeable seasonal temperature and bolt fracture cause the redistribution of interface friction and threaten the joint safety. Therefore, this study carried out finite element analysis on the interface friction considering the influence of seasonal temperature and bolt fracture. Through finite element analysis, the simulation of interface friction under seasonal temperature revealed the distribution of temperatureinduced interface friction in different areas and locations. Further simulation of fractured bolts revealed the influence of quantity and location of fractured bolts on the redistribution of interface friction. Finally, the interface frictions in the bolted joint were evaluated using limit state equations. The results showed that: 1) the quantity and location of fractured bolts cause obvious redistribution of interface friction in the bolt-fractured areas; 2) the quantity and location
\end{abstract}

\footnotetext{
* Corresponding author. E-mail: tbh119@cumt.edu.cn

Gaoxin WANG (ORCID 0000-0003-0007-4053)

Youliang DING (ORCID 0000-0002-0774-426X) 
of fractured bolts have slight effect on the total interface friction in the whole splice plate; 3) the reduced interface friction in the bolt-fractured areas was transferred to the areas without bolt fracture, producing little change in the total interface friction;4) all the splice plates had abundant safety margin after analysis of their limit state equations.

Keywords: fractured bolt, friction redistribution, joint-bolted bridge, safety evaluation, temperature effect.

\section{Introduction}

Bolts have been widely used in the joints to connect the members of steel structures (Bednarz III \& Zhu, 2014; Ju\& Oh, 2016; Wu, Cao, Han, \& Ren, 2017; Yeum \& Dyke, 2015), especially in the steel truss bridges such as the Dashengguan Railway Bridge (Jin, 2013). For the frictional bolt joint with high strength (FBJHS), the interface friction on the contact surfaces of splice plates plays a critical role in transferring the internal forces from one steel truss member to another. However, the bolt fracture is commonly found at the bridge site due to various influence factors such as fatigue vibration, environmental corrosion, and excessive twisting. For example, the Dashengguan Railway Bridge is one long-span steel truss arch bridge (Figure 1), and friction-type high-strength bolt is used in this bridge to connect the numerous truss members, but from December 2010 to March 2016 a total of 277 fractured bolts were found from this bridge (Zhu, 2016). Besides, the bridge is mainly subject to uniform temperature field from 12 a.m. to 6 a.m. (Wang \& Ding, 2015). Figure 2 shows the monitoring seasonal temperature data between 12 a.m. and 6 a.m. from March to November in 2013 that presents an apparent seasonal change from $2.8^{\circ} \mathrm{C}$ to $30.7{ }^{\circ} \mathrm{C}$. The combined effect of bolt fracture and noticeable seasonal temperature seriously threatens the safety of FBJHS. So, it is significant to conduct a safety evaluation on the FBJHS of steel truss bridge under this condition.

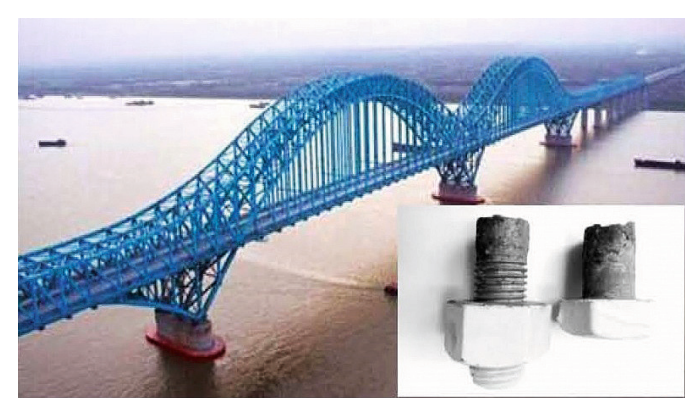

Figure 1. The Dashengguan Railway Bridge and bolt fracture 
Many experiments and finite element simulations have been carried out to study the mechanical and fatigue performance of bolted joints (Benhamena, Amrouche, Talha, \& Benseddiq, 2012; Jiménez-Peña, Talemi, Rossi, \& Debruyne, 2017; Juoksukangas, Lehtovaara, \& Mäntylä, 2016). Jiménez-Peña, Talemi, Rossi, \& Debruyne (2017) investigated the failure mechanism of fretting fatigue in the bolted joints subjected to different levels of pre-tension. Benhamena, Amrouche, Talha, \& Benseddiq (2012) studied the effect of contact forces on fretting fatigue behaviour of bolted splice plates. Zou, Feng, \& Wang (2018) investigated the behaviour of bolted shear connections for fibre-reinforced polymer (FRP) concrete hybrid beams. Su, Yang, \& Bradford (2016) presented an investigation of the static behaviour of group-arranged stud-bolt hybrid shear connection in long-span segmental bridges. However, the bolted joints in these studies usually contain only a small number of splice plates and bolts, and these studies rarely take the bolt fracture and seasonal temperature into consideration. For the FBJHS in the long-span steel truss bridges, numerous bolts and splice plates are usually employed in the bolted joints. For example, one top chord member in the Dashengguan Railway Bridge contains 16 splice plates and over 700 friction-type high-strength bolts. Concerning such FBJHS, relevant studies usually focus on the interface friction in the bolted joint before bolt fracture, and it is difficult to answer whether the bolted joint still satisfies the safety demand after bolt fracture.

Therefore, this research will thoroughly focus on the interface friction of FBJHS in the steel truss bridge with consideration of both bolted fracture and seasonal temperature. What is mentioned is that
The Interface Friction in the Friction-Type Bolted Joint of Steel Truss Bridge: Case Study

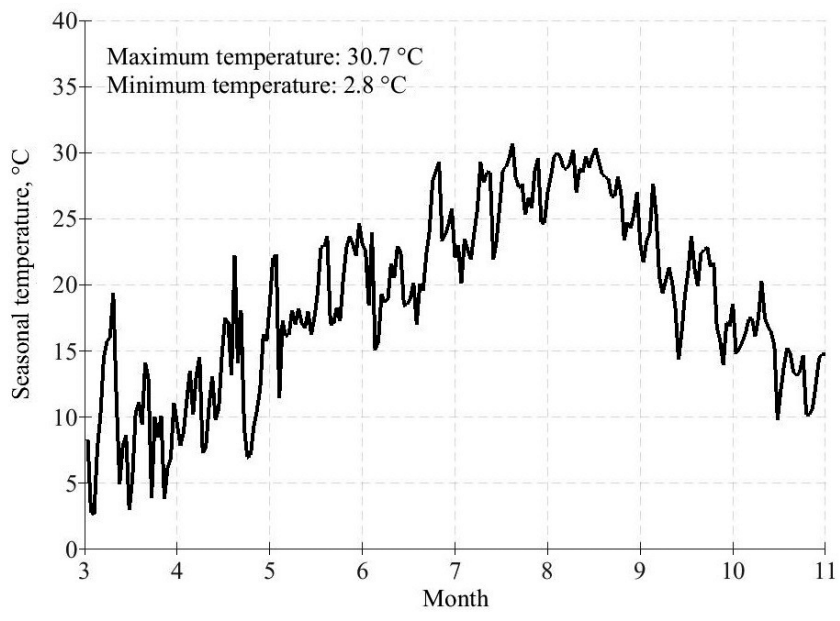

Figure 2. Monitoring seasonal temperature 
the interface friction is difficult to be monitored and collected at the bridge site. So finite element simulation is one effective procedure to study the interface friction in the bolted joint. In detail, one whole-bridge model and one refined bolted joint model are combined to simulate the interface friction for the Dashengguan Railway Bridge using LS-DYNA. LS-DYNA well simulates the interface contact process among splice plates, that has been widely used in the bolted joint study (Kim \& Lee, 2015; Noh, Lee, \& Park, 2013; Wang, Ding, Song, Wu, Yue, \& Mao, 2015). Concerning the verification of finite element model, considering that the role of interface friction is to transfer the internal forces in the truss members, the monitoring strain data under seasonal temperature is employed to validate the finite element model. Specifically, if the interface friction well transfers the internal forces in the truss members, the simulated strain will agree with the monitoring strain under the same seasonal temperature.

Through this study, the redistribution of interface friction caused by the quantity and location of fractured bolts in the FBJHS is revealed. Furthermore, the safety evaluation method for the interface friction in the FBJHS, considering both bolt fracture and the seasonal temperature is put forward. The results provide a useful reference for the frictional steel connection design of high-strength bolts, especially for the longspan steel truss bridges. What is mentioned is that the results are only subjected to the seasonal temperature, and the results ignore the influence of trains and gradient temperature. Such a case usually occurs between 12 a.m. and 6 a.m., and during this period the temperature field in the Dashengguan Railway Bridge is uniform, and the bridge traffic is closed either (Wang \& Ding, 2015). However, during the daytime, high-temperature gradient exists in the Dashengguan Railway Bridge (Wang \& Ding, 2015), and many trains pass over the bridge. Therefore, future research work will focus on more influence factors including temperature gradient, running trains and bolt fracture for the safety evaluation of the FBJHS.

\section{Finite element modelling}

\subsection{The whole-bridge model and refined bolted joint model}

By referring to the design drawing of the Dashengguan Railway Bridge (Ding, Wang, Hong, Song, Wu, \& Yue, 2017), the whole-bridge model and refined bolted joint model are modelled using the computer software LS-DYNA, as shown in Figure 3, where the bolted joint model is located at the top chord member $P_{1} P_{2}$ from the middle span of the 
Dashengguan Railway Bridge. In the whole-bridge model, the truss members and transverse stiffening beams under bridge deck are modelled by the Belytschko-Schwer resultant beam element that contains two six-degree-of-freedom nodes. The bridge deck is modelled by the shell element that contains four six-degree-of-freedom nodes. The supports $A, B, C, E, F$ and $G$ of the Dashengguan Railway Bridge are constrained in the $z$-translational and $y$-translational directions and are free to move in the $x$-translational direction. The support $D$ is constrained in all the three translational directions. In the bolted joint model, the plates of the top chord member and splice plates are modelled by Belytschko-Lin-Tsay shell element. The friction-type high-strength bolts are modelled by the solid element containing constant stress. The whole-bridge model and bolted joint model are combined by coupling the boundary nodes at the locations $P_{1}$ and $P_{2}$.

For the whole-bridge finite element model, Young and shear moduli are $205.9 \mathrm{GPa}$ and $79.2 \mathrm{GPa}$, respectively; the density is $7853 \mathrm{~kg} / \mathrm{m}^{3}$; the Poisson ratio is 0.3 ; the thermal expansion coefficient is $0.000013 /{ }^{\circ} \mathrm{C}$. For the friction-type high-strength bolt in the joint model, Young and shear moduli are $206 \mathrm{GPa}$ and $79.38 \mathrm{GPa}$, respectively; the density is $7820 \mathrm{~kg} / \mathrm{m}^{3}$ (bolt screw) or $7890 \mathrm{~kg} / \mathrm{m}^{3}$ (bolt nut and washers); the Poisson ratio is 0.28 ; the thermal expansion coefficient is $0.0000125 /{ }^{\circ} \mathrm{C}$; the clamping force is $355 \mathrm{kN}$. For the splice plate in the joint model,

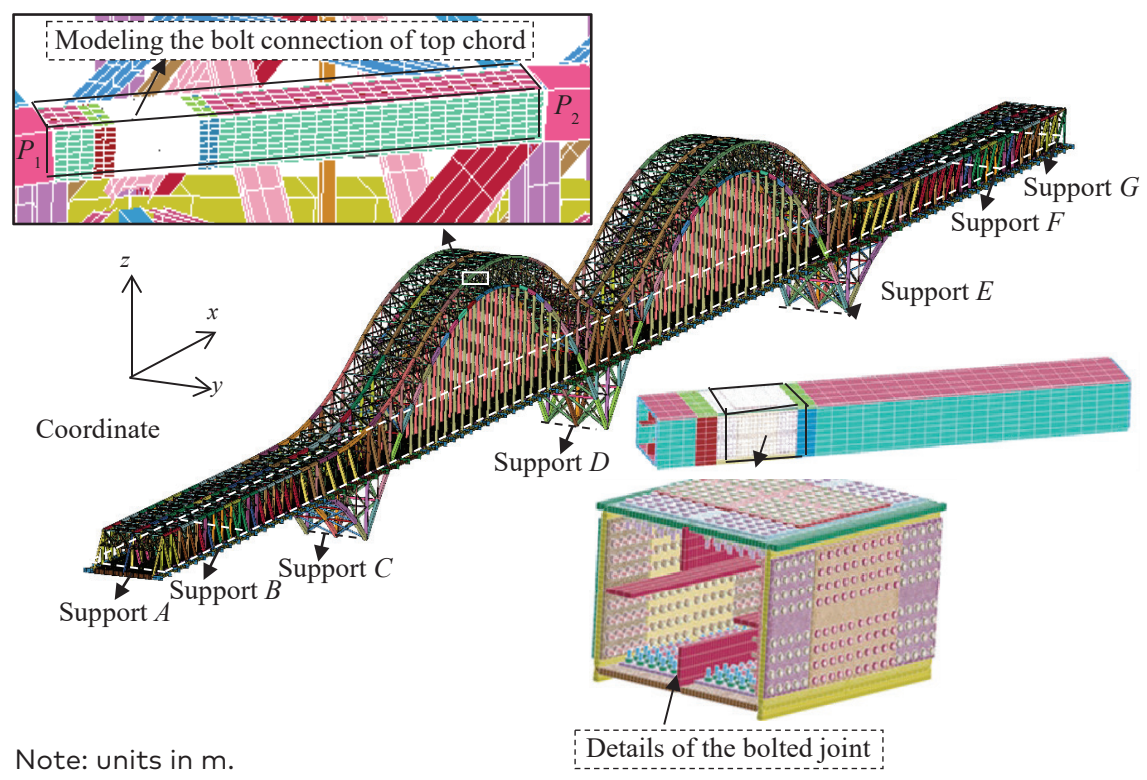

The Interface Friction in the Friction-Type Bolted Joint of Steel Truss Bridge: Case Study

Figure 3. The whole-bridge model and bolted joint model 


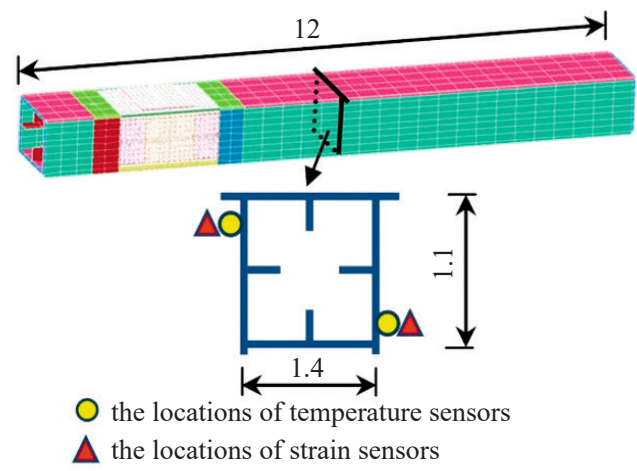

a) location of temperature and strain sensors

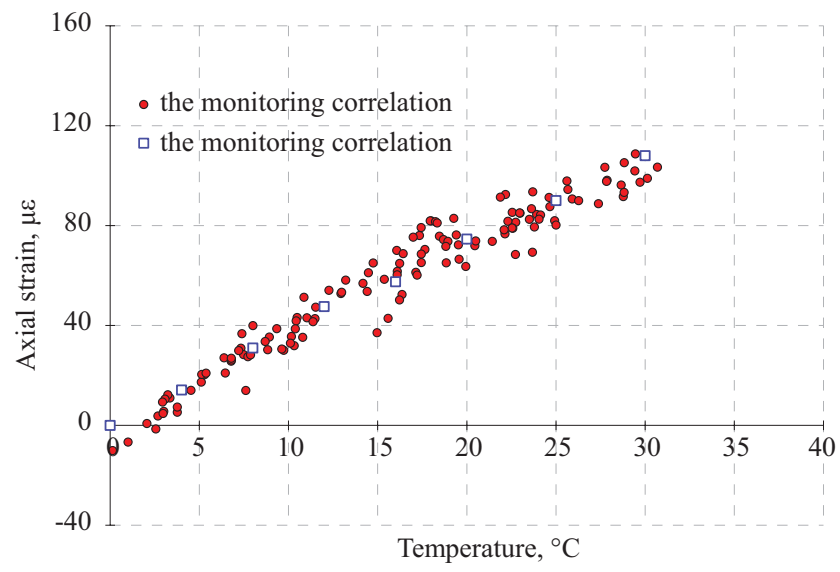

b) the monitoring and simulated correlations between axial strain and temperature

Note: units in $\mathrm{m}$.

Figure 4. Validation of finite element model

moduli of Young and Shear are $206 \mathrm{GPa}$ and $79.38 \mathrm{GPa}$, respectively; the density is $7850 \mathrm{~kg} / \mathrm{m}^{3}$; the Poisson ratio is 0.28 ; the thermal expansion coefficient is $0.000013 /{ }^{\circ} \mathrm{C}$; the static friction coefficient is 0.45 .

As mentioned earlier, the interface friction is hardly monitored and collected from the bridge site to validate the finite element model. However, considering that the role of interface friction is to transfer the internal forces in the truss members, the monitoring strain data under uniform temperature field is employed to validate the finite element model instead of interface friction. Specifically, if the interface friction 
well transfers the internal forces in the truss members, the simulated strain will agree with the monitoring strain under the same uniform temperature. The monitoring locations of temperature and strain are shown in Figure 4a, and the monitoring correlation between strain and temperature is shown in Figure 4b (Ding, Wang, Hong, Song, Wu, \& Yue, 2017). In the monitoring correlation, the strain at temperature $0{ }^{\circ} \mathrm{C}$ is offset to $0 \mu \varepsilon$. Figure $4 \mathrm{~b}$ shows that the simulated correlation is like the monitoring correlation, verifying that the finite element model is feasible for analysis.

\subsection{Details of splice plates and bolt group}

Specifically, the bolted joint has a total number of 16 splice plates from splice plate $B$ to splice plate $Q$, as shown in Figure 5 , and each side in the cross-section of the bolted joint has four splice plates (i.e. two splice plates inside and two splice plates outside). As reported by the design drawing of the Dashengguan Railway Bridge, all the splice plates are made of $\mathrm{Q} 420 \mathrm{qE}$ steel (i.e. the tensile strength is $550 \mathrm{MPa}$, and the yield strength is $410 \mathrm{MPa}$ ). Splice plates $C, D, G, H, K, L$, and $P$ have two contact interfaces, and splice plates $B, E, F, I, J, M, N$, and $Q$ have one contact interface. These contact interfaces transfer normal interface force and shear interface force from one splice plate to another by
The Interface Friction in the Friction-Type Bolted Joint of Steel Truss Bridge: Case Study

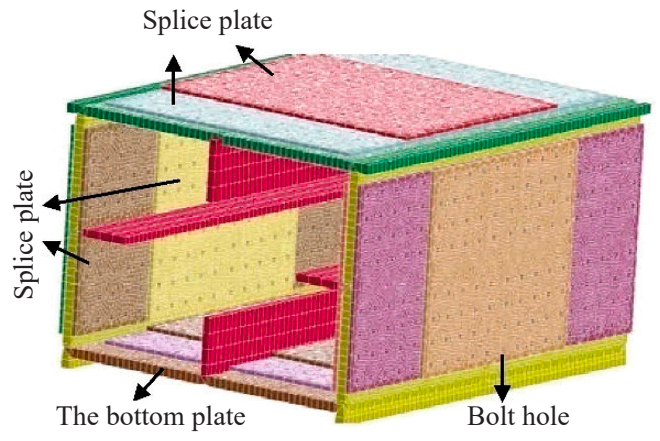

a) isometric view of the multi-layer splice plates
WDS the cross section of top chord the splice plate

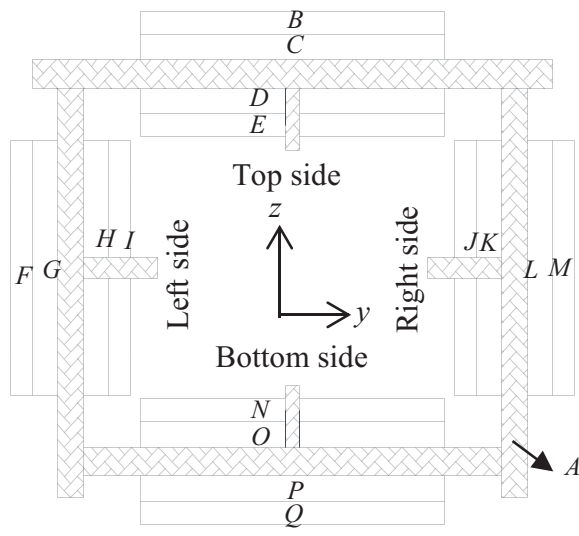

b) the drawing of the multi-layer splice plates

Figure 5. The details of multi-layer plates 


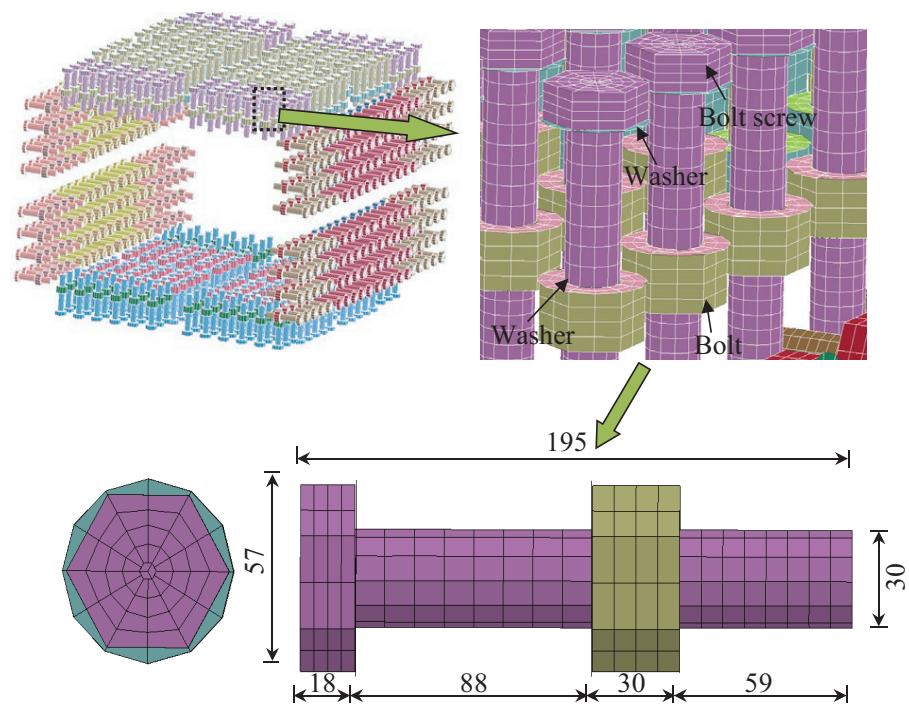

Note: units in $\mathrm{mm}$.

Figure 6. The details of the bolt group

calculating the automatic surface-to-surface contact algorithm in the LS-DYNA. As reported by the overview of the splice plates in the design drawing, the static friction coefficient of the contact interface is 0.45 . The thickness of plate $A$ is $48 \mathrm{~mm}$, and the thickness of splice plates $B \sim P$ is $20 \mathrm{~mm}$, respectively.

This bolted joint contains 728 hexagonal bolts, as shown in Figure 6. The dimension of each bolt is M30 (i.e. the diameter of bolt screw is $30 \mathrm{~mm}$ ), and its mechanical performance is $10.9 \mathrm{~s}$ (i.e. the tensile strength is about $1040 \mathrm{MPa} 1240 \mathrm{MPa}$, and the yield strength is $940 \mathrm{MPa})(\mathrm{GB} / \mathrm{T}$ 1231-2006 Specifications of High Strength Bolts with Large Hexagon Head, Large Hexagon Nuts and Plain Washers for Steel Structures). Each bolt consists of four parts: bolt screw, bolt nut and two plain washers. As reported by the design drawing of the Dashengguan Railway Bridge, the bolt screw is made of 35VB steel, and the bolt screw and washers are made of No. 45 steel $(G B / T$ 12312006). The contact interfaces of each bolt include a screw-washer interface, plate-washer interface, and nut-washer interface. These contact interfaces mainly transfer normal interface force, and the normal interface force is calculated using the automatic surface-tosurface contact algorithm in LS-DYNA. Each bolt is preloaded with a clamping force of $355 \mathrm{kN}$. 


\subsection{The calculation method of interface friction}

Seasonal temperature induces interface friction. For example, the two parts of splice plate $A$ are connected by the splice plates $M, L, K$ and $J$ with friction-type high-strength bolts, as shown in Figure 7. Although the loads on the bridge include gravity, temperature, wind, rain, the change of tensile stress in the splice plate $A$ is mainly caused by seasonal temperature between 12 a.m. and 6 a.m. (Ding, Wang, Hong, Song, Wu, \& Yue, 2017). The tensile stress further induces interface friction on the contact interfaces of splice plate $L$, as shown in Figure 8, where $f_{L M}$ - the interface friction between splice plate $L$ and splice plate $M$, and $f_{L A}$ - the interface friction between splice plate $L$ and plate $A$. The total interface friction $f$ for the splice plate $L$ is $f=f_{L M}+f_{L A}$. Furthermore, because uniform seasonal temperature primarily induces axial stress in the top chord member (Ding, Wang, Hong, Song, Wu, \& Yue, 2017), the principal direction of interface friction is the $x$-axial direction, as shown in Figure 8.

Splice plate $L$ consists of 31006 shell elements, and each shell element contains interface friction. The total interface friction of splice plate $L$ can is obtained by adding together all the interface frictions in every shell element, but this requires extensive calculation. Therefore, the resultant normal force in the cross-section of splice plate $L$ is utilised to efficiently acquire the total interface friction, as shown in Figure 9. The axial stress in each shell element multiplied by its cross-sectional area is the axial force in each shell element. The integration of axial forces in cross-section $p_{11} q_{11}$ for all the shell elements is the resultant normal force $F_{x}$, as shown in Figure 9. As reported by the principle of static equilibrium, the resultant normal force is equal to the total interface friction $f$, that is, $F_{x}=f$. Furthermore, the total interface friction in the specified area $p_{1} p_{11} q_{11} q_{1}$ of splice plate $L$ is equal to the resultant normal force $F_{x}$ in the cross-section $p_{11} q_{11}$ of splice plate $L$.

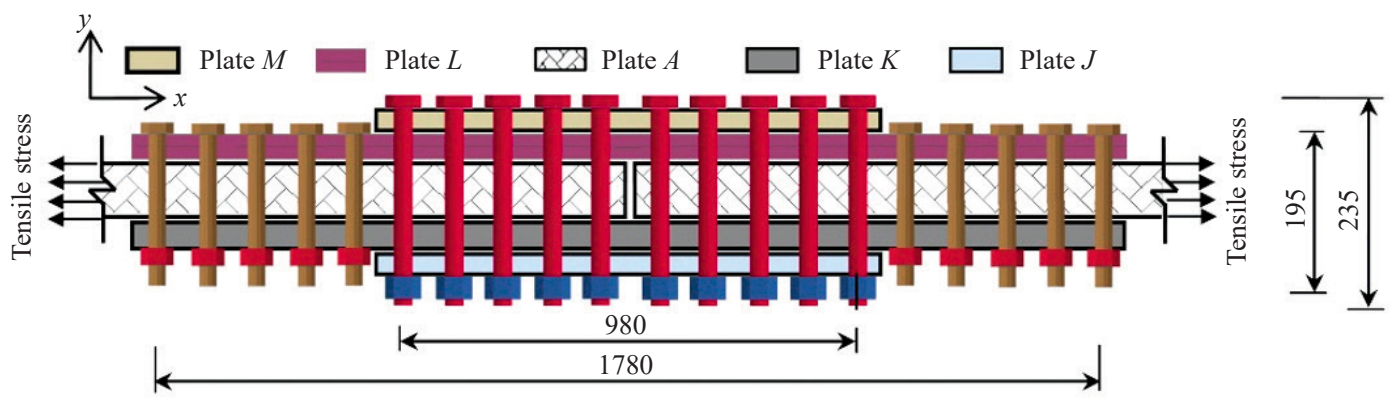

Note: units in $\mathrm{mm}$.

Figure 7. The details of bolt connection for plate $A$ 


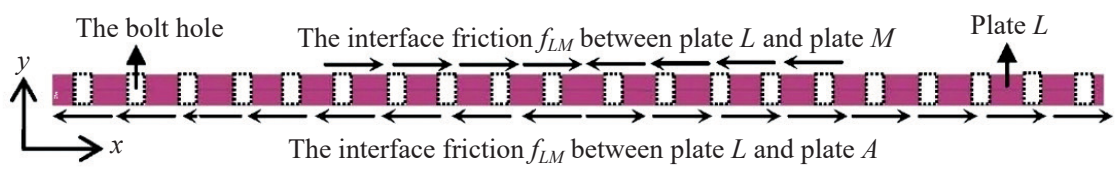

Figure 8. The distribution of interface friction on two contact interfaces of splice plate $L$

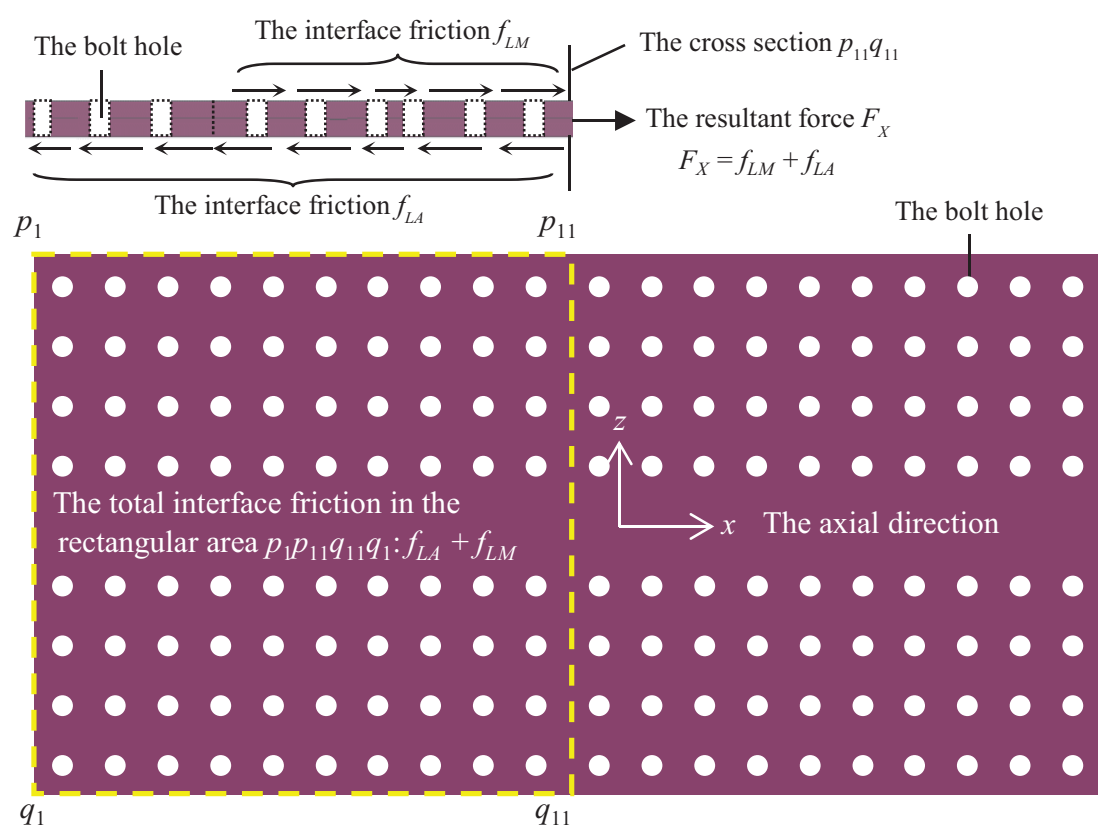

Note: units in $\mathrm{mm}$.

Figure 9. The calculation method of interface friction

\section{The influence of seasonal temperature}

\subsection{The time-domain change trend of interface friction}

The clamping force from friction-type high-strength bolts produces evident pressure on the interface surfaces of the splice plates. Figure 10a shows the left symmetric part of the interface pressure on the left side of splice plate $L$ (the splice plate $L$ has two sides of contact surfaces, i.e. left side and right side as shown in Figure 5b), and it shows that:

1. The interface pressure is mainly centred on bolt holes; 


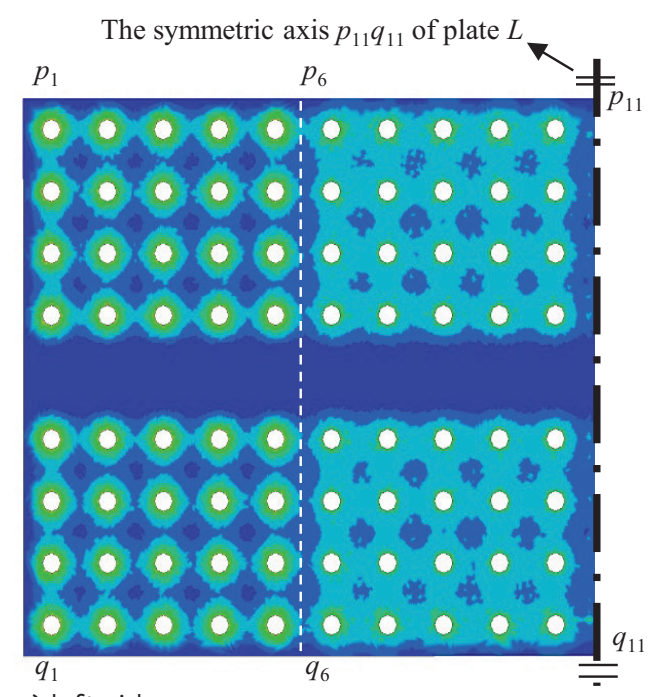

a) left side

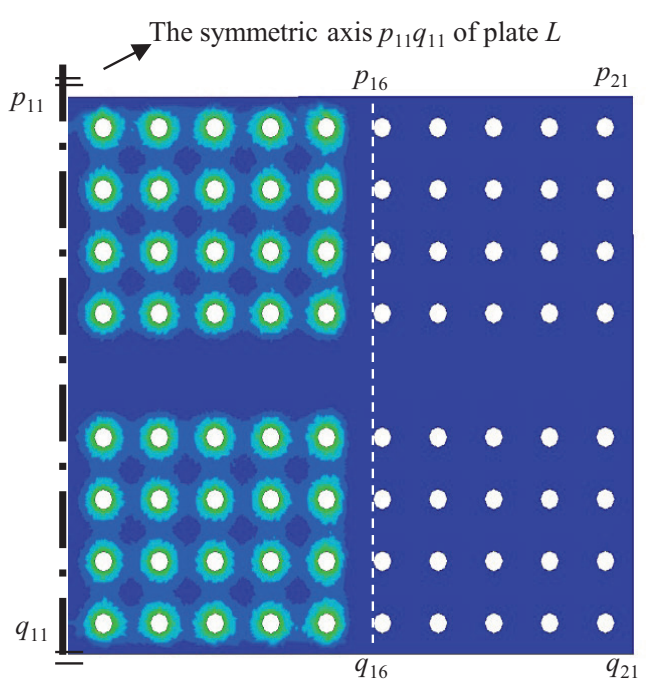

b) right side

Figure 10. The interface pressure on the two sides of splice plate $L$

2. The interface pressure in the area $p_{6} p_{11} q_{11} q_{6}$ is weaker than that in the area $p_{1} p_{6} q_{6} q_{1}$ because of the pressure diffusion in the splice plates $M$ and $L$, so the two-layer splice plates effectively diffuse the pressure concentration.

Besides, Figure 10b also shows the right symmetric part of the interface pressure on the right side of splice plate $L$, and it seems that only the area $p_{11} p_{16} q_{16} q_{11}$ contains interface pressure because of the contact area between $L$ and $M$ in the zone $p_{16} p_{21} q_{21} q_{16}$ is 0 .

Under the effect of interface pressure and seasonal temperature, the splice plates are mainly subjected to axial stress in the $x$ direction, denoted by $x$-stress. Figure 11 shows the tensile stress of splice plate $L$ when the seasonal temperature increases $20{ }^{\circ} \mathrm{C}$. The tensile stress presents a gradual increase in $x$-stress from a cross-section $p_{1} q_{1}$ to cross-section $p_{11} q_{11}$ along the $x$ direction. Using the calculation method of interface friction, the interface friction in the area $p_{1} p_{11} q_{11} q_{1}$ of splice plate $L$ is calculated, and the result of interface friction from March 2013 to November 2013 is shown in Figure 12. It seems that the changing trend of interface friction is like the seasonal monitoring temperature by comparison to Figure 2. The maximum and minimum interface frictions are $547.7 \mathrm{kN}$ and $47.1 \mathrm{kN}$, respectively.

Since the interface friction and monitoring seasonal temperature present similar change trends, their correlation is further plotted in Figure 13. It shows obvious linear characteristics. Although this 


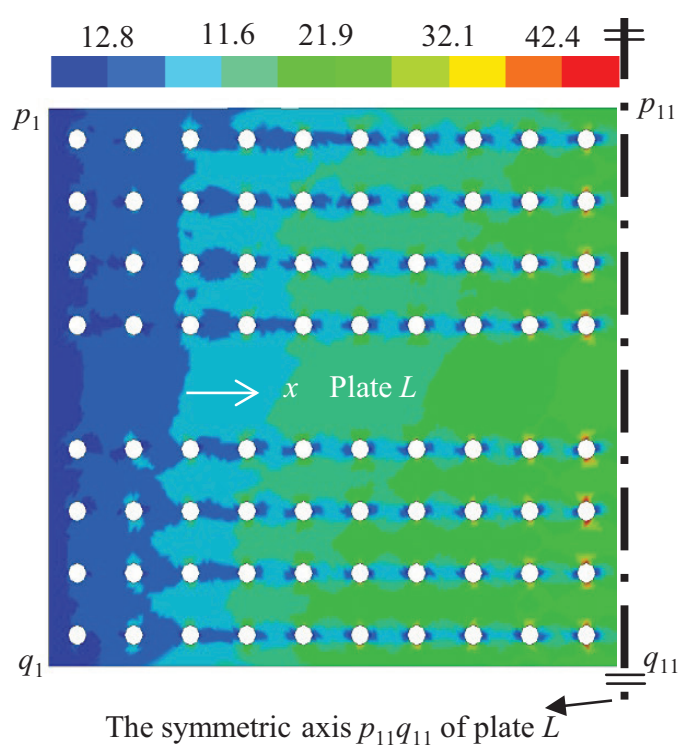

Note: units in MPa.

Figure 11. The -stress in the splice plate $L$

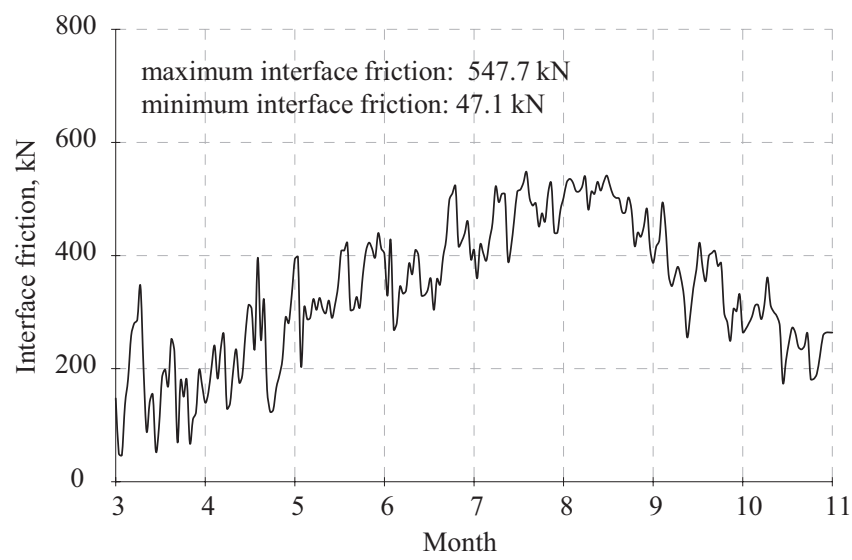

Figure 12. The interface friction in the area

linear characteristic is difficult to be directly verified using field test data or monitoring data, many research results have verified that the temperature-induced effects (such as strain and displacement) have linear correlation with temperature field (Ding, Wang, Hong, Song, Wu, \& Yue, 2017; Wang, Ding, Song, Wu, Yue, \& Mao, 2015). In this research, the interface friction also has a linear correlation with temperature, 


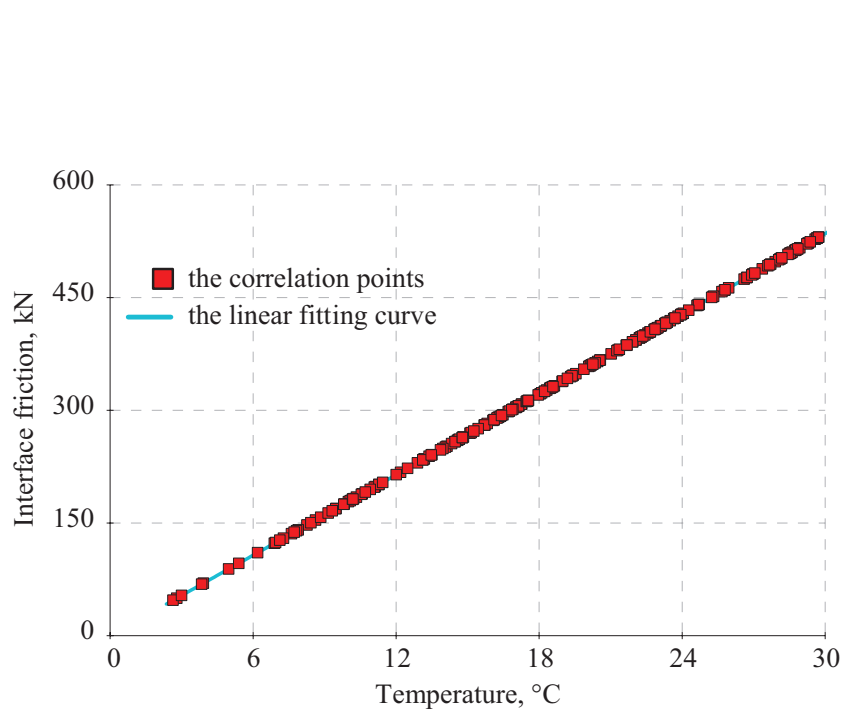

Figure 13. The correlation between friction and temperature

as shown in Figure 13. Furthermore, a linear equation is used to fit the linear correlation using the least-squares method, and the fitted value of the linear slope is $17.84 \mathrm{kN} /{ }^{\circ} \mathrm{C}$. It means that the interface friction in the area $p_{1} p_{11} q_{11} q_{1}$ can increases $17.84 \mathrm{kN}$ as the seasonal temperature increases $1{ }^{\circ} \mathrm{C}$. The linear slope is further used as one analytical index to study other influence factors, such as the influence of quantity and location of fractured bolts.

\subsection{The interface frictions in different areas of splice plates}

The left symmetric part of splice plate $L$ is divided into 11 areas, as shown in Figure $14 \mathrm{a}$, where the area $p_{i} p_{i+1} q_{i+1} q_{i}$ is denoted by $S_{i}$ and the area $p_{i} p_{i+1} q_{i+1} q_{i}$ is denoted by $C_{i}$. Using the calculation method of interface friction, the interface friction in each area $C_{i}$ is obtained, and then the linear slope in the area $C_{i}$ is further fitted, as shown in Figure $14 \mathrm{~b}, i=1,2, \ldots, 11$. It seems that the linear slope gradually increases from $C_{1}$ to $C_{11}$, and the maximum linear slope is $17.84 \mathrm{kN} /{ }^{\circ} \mathrm{C}$ in the area $C_{11}$. Furthermore, the linear slope in each area $S_{i}$ is calculated using the linear slope in the area $C_{i+1}$ minus the linear slope in the area $C_{i}$, as shown in Figure 14c. It seems that the linear slope gradually decreases from $S_{1}$ to $S_{7}$, and then gradually increases from $S_{1}$ to $S_{10}$. Itindicates that the interface frictions in different areas of the splice plate $L$ are different, and the interface frictions in the areas $p_{1} p_{2} q_{2} q_{1}$ and $p_{10} p_{11} q_{11} q_{10}$ are larger than that in the area $p_{7} p_{8} q_{8} q_{7}$. The interface friction relates to the load transfer ratio, and larger interface friction in the area $S_{i}$ means larger load transfer ratio in the area $S_{i}$. Some results have shown that the load transfer ratios in the two-end
The Interface Friction in the Friction-Type Bolted Joint of Steel Truss Bridge: Case Study 
The symmetric axis $p_{11} q_{11}$ of plate $L$

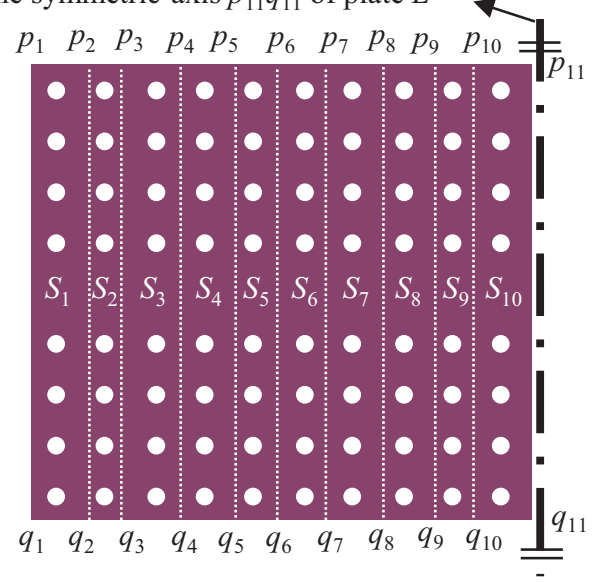

a) the division of left symmetric part of splice plate $L$

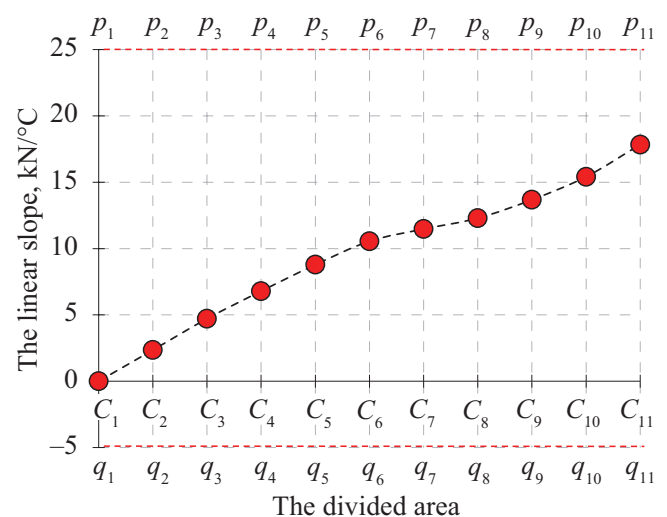

b) the linear slope in the divided area $C_{i}$

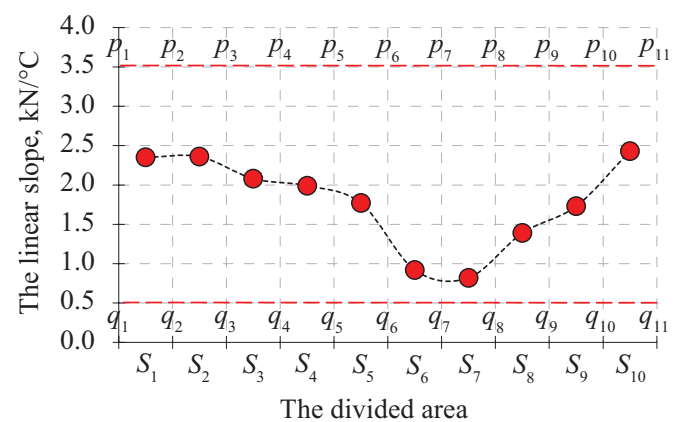

c) the linear slope in the divided area $S_{i}$

Figure 14. The linear slopes in different divided areas of splice plate $L$ 
Figure 15. The linear slopes of different splice plates

areas (i.e. $S_{1}$ and $S_{10}$ here) are larger than the ones in the middle areas (i.e. $S_{6}$ and $S_{7}$ here) that is similar to saddle shape (Xu, 2011; Zhang, Wang, Huang, \& Liu, 2010). Those results agree with the distribution of interface friction in this research.

As shown in Figure $14 \mathrm{~b}$, the interface friction in the area $C_{11}$ is the largest of all the areas. Furthermore, using the calculation method of interface friction, the most significant interface frictions in the other splice plates are calculated, and then the linear slopes corresponding to the largest interface frictions are further obtained, as shown in Figure 15. It seems that the linear slopes of splice plates are divided into two groups: for the splice plates $C, D, G, H, K, L$, and $O$, the linear slopes have similar values; for the splice plates $B, E, F, I, J, M, N$, and $Q$, the linear slopes have similar values. The average value in the first group is $17.4 \mathrm{kN} /{ }^{\circ} \mathrm{C}$, and the average value in the second group is $4.0 \mathrm{kN} /{ }^{\circ} \mathrm{C}$, so the average linear slope in the first group is about 4 times larger than that in the second group, indicating that the interface frictions caused by seasonal temperature mainly exist in the splice plates $C, D, G, H, K, L$, and $O$.

\section{The influence of bolt fracture}

\subsection{Two influence factors: the quantity and location of fractured bolts}

As mentioned earlier, the bolt fracture in the Dashengguan Railway Bridge occurs every year in the real service environment (Zhu, 2016). Besides, as reported by the inspection results of fractured bolts in the Dashengguan Railway Bridge (Jin, 2013), bolt fracture occurs randomly because of complex influence factors. Therefore, providing that eight bolts be fractured, as shown in Figure 16, the fractured bolts are directly 
removed from the finite element model to simulate the influence of fractured bolts. Then, the seasonal temperature increases $20^{\circ} \mathrm{C}$, and the $x$-axial tensile stress in the splice plate $L$ is plotted in Figure 16. It shows that the tensile stress values change little by comparison to the results before bolt fracture in Figure 11. Furthermore, Figure 17 shows the changing trend of total interface friction in the area $p_{1} p_{11} q_{11} q_{1}$ induced by both seasonal monitoring temperature and eight fractured bolts, and it seems that it is very close to the changing trend before bolt fracture. Therefore, it infers that eight fractured bolts have only a slight influence on the total interface friction.

Considering that, eight fractured bolts have a slight influence on the interface friction, a larger number of fractured bolts are considered in this study. Since the quantity of fractured bolts in a period is random in the real service environment (Jin, 2013), the number of fractured bolts is simulated under five analytical cases, and the quantity of fractured bolts in each case is hypothetically $8,16,24,32$, and 40 , respectively. For each certain quantity of fractured bolts, considering that their fracture location is also random (Jin, 2013), 12 possible fracture locations are considered for each case. The possible locations for each case are determined using a random sampling method. Concerning the random sampling method, the location of every bolt in the left symmetric part of splice plate $L$ is numbered from 1 to 80 one by one, and then 12 random

The locations of fractured bolts

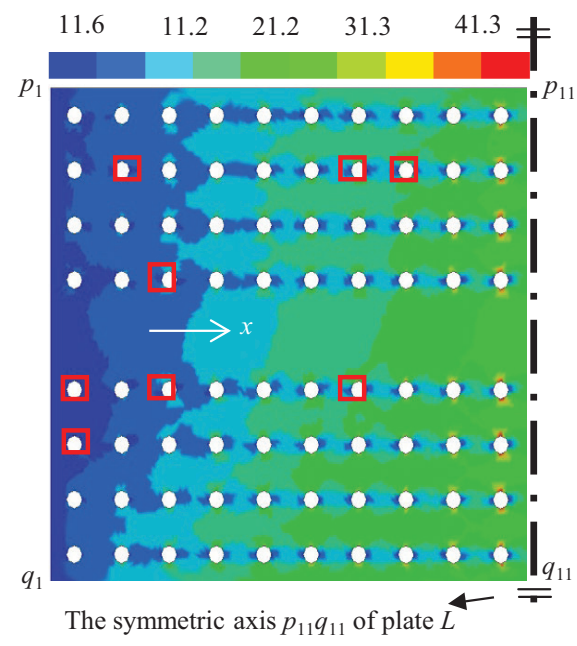

Note: units in MPa.

Figure 16. The $x$-axial stress in the splice plate $L$ 


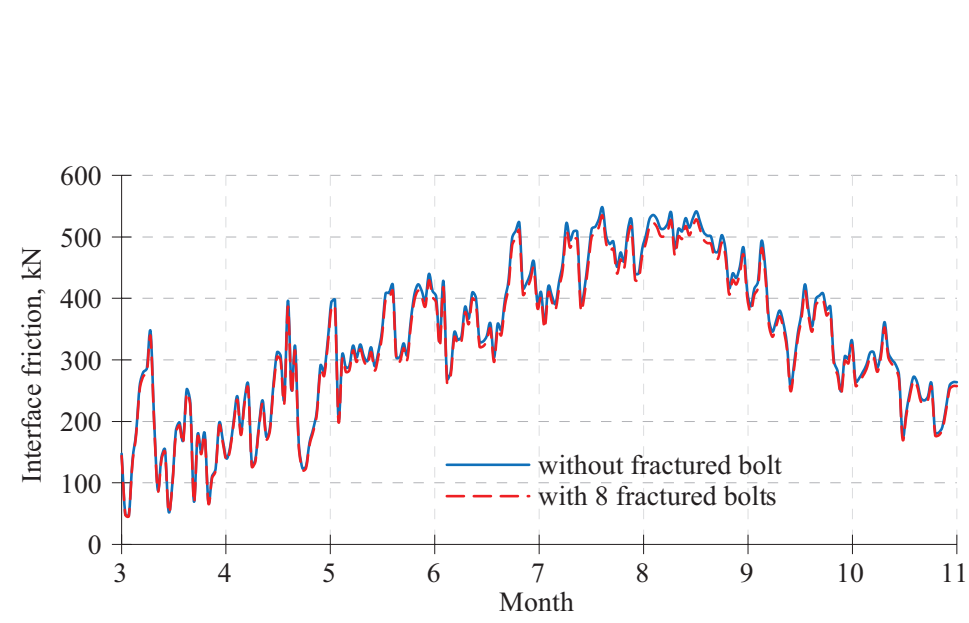

The Interface Friction in the Friction-Type Bolted Joint of Steel Truss Bridge: Case Study

Figure 17. The friction force in the area

numbers are sampled from intervals $[1,80]$. The random numbers are treated as the locations of fractured bolts.

Using the calculation method of interface friction, the total interface friction in the area $p_{1} p_{11} q_{11} q_{1}$ of splice plate $L$ is calculated for each analytical case. Then, the linear slope of the correlation between the total interface friction and the seasonal temperature is fitted. Finally, 12 linear slopes corresponding to 12 possible fracture locations for each case are obtained, and the average linear slope (ALS) for each case is calculated to study the influence of fracture quantity on interface friction, as shown in Figure 18. It seems that the ALS gradually decreases as the fracture quantity increases, but the range of decrease is minimal, from $17.84 \mathrm{kN} /{ }^{\circ} \mathrm{C}$ to $16.86 \mathrm{kN} /{ }^{\circ} \mathrm{C}$, indicating that the influence of the quantity of fractured bolt on the total interface friction in the splice plate $L$ is ignored. The 12 linear slopes minus the ALS in each case is

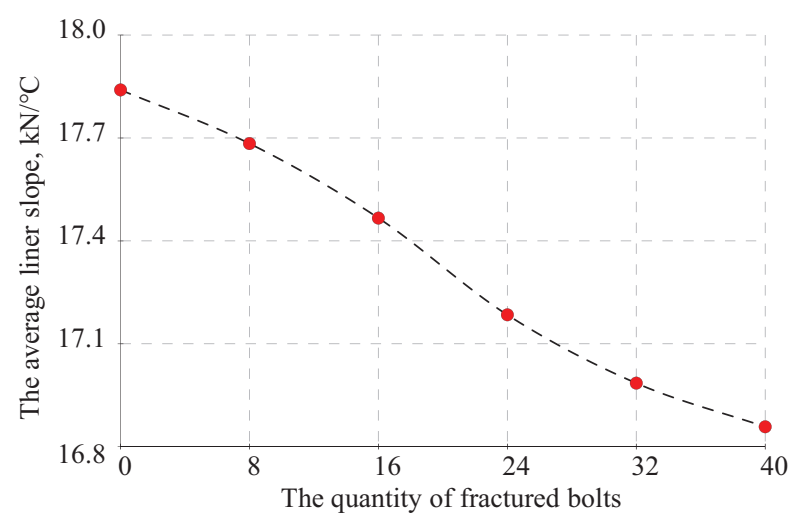

Figure 18. The influence of fracture quantity 


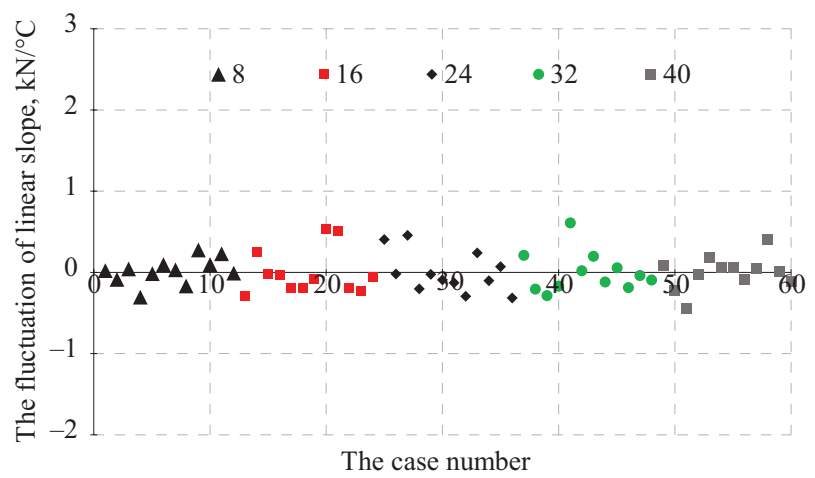

Figure 19. The influence of fracture location

the fluctuation of linear slopes that reflects the influence of fracture location on interface friction, as shown in Figure 19. It seems that the fluctuation of linear slopes is one stationary process, and the fluctuation range is minimal, from $0.61 \mathrm{kN} /{ }^{\circ} \mathrm{C}$ to $-0.44 \mathrm{kN} /{ }^{\circ} \mathrm{C}$. The fluctuation range indicates that it is reasonable to ignore the influence of the location of fractured bolts on the total interface friction in the splice plate $L$ is ignored.

\subsection{The redistribution of interface friction after bolt fracture}

The reason why bolt fracture has little effect on the total interface friction in the area $p_{1} p_{11} q_{11} q_{1}$ is the redistribution of interface friction after bolt fracture. Assume that 32 bolts are fractured in the areas $p_{3} p_{5} q_{5} q_{3}$ and $p_{7} p_{9} q_{9} q_{7}$ of splice plate $L$, as shown in Figure 20a. Then, the interface friction in the area $C_{i}$ of splice plate $L$ is obtained using the calculation method of interface friction, and the linear slope of the correlation between the interface friction and the seasonal temperature is obtained as shown in Figure 20b. Compared to the linear slope without bolt fracture, it has seen that:

1. After bolt fracture, the linear slope has a different trend from $C_{1}$ to $C_{11}$, namely the redistribution of interface friction after bolt fracture;

2. The linear slope in the area $C_{11}$ changes little after bolt fracture, indicating that the bolt fracture has little effect on the total interface friction in the area $p_{1} p_{11} q_{11} q_{1}$. Furthermore, the interface friction in each divided area $S_{i}$ is plotted in Figure 20c. It shows that after bolt fracture the linear slopes become lower in the boltfractured areas $S_{3}, S_{4}, S_{7}$ and $S_{8}$, and become larger in the areas $S_{2}$, 
The Interface Friction in the Friction-Type

The locations of fractured bolts

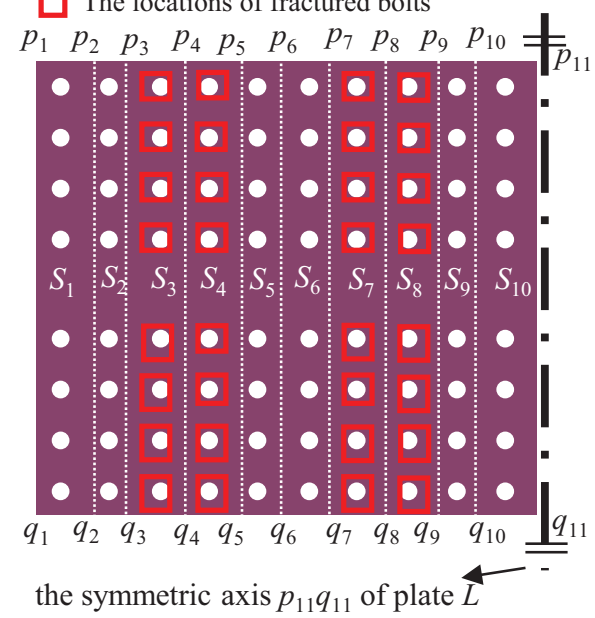

Bolted Joint of Steel

Truss Bridge: Case Study

a) the division of splice plate $L$

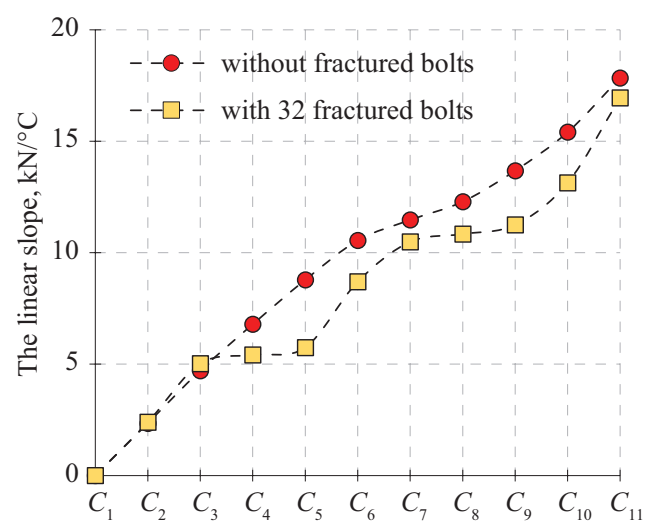

The divided area

b) the redistribution of linear slope in the area $C_{i}$

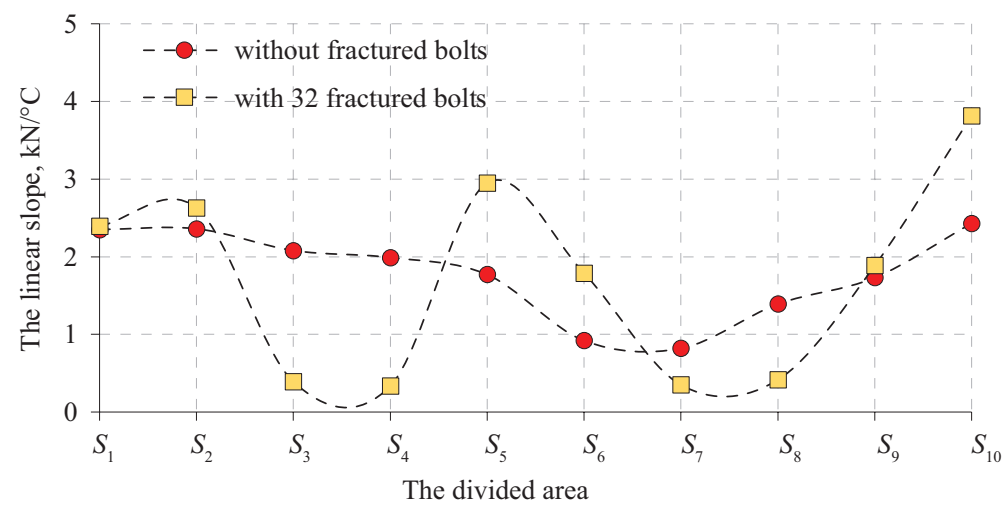

c) the redistribution of linear slope in the area $S_{i}$

Figure 20. The redistribution of linear slopes caused by 32 fractured bolts 
$S_{5}, S_{6}, S_{9}$ and $S_{10}$. This means that the reduced linear slopes in boltfractured areas are transferred into the areas without fractured bolts, thus producing little change in the total interface friction in the area $p_{1} p_{11} q_{11} q_{1}$.

\section{Safety evaluation analysis}

\subsection{Safety evaluation method}

For the FBJHS, the interface friction among splice plates transfers the internal force of the top chord member, so the abnormal variation in interface friction in real service environment threatens the safety of bolt connection. The influence of seasonal temperature together with the bridge gravity on the total interface friction in the splice plate is expressed as follows:

$$
f_{\text {total }}=k\left(T-T_{0}\right)+f_{g},
$$

where $f_{\text {total }}$ - the total interface friction of one splice plate; $k$ - the linear slope of correlation between interface friction and seasonal temperature; $T$ - the seasonal monitoring temperature; $T_{0}$ - the reference temperature when the temperature-induced interface friction is $0 \mathrm{kN} ; f_{g}$ - the interface friction of one splice plate caused by bridge gravity. Unfortunately, $T_{0}$ is difficult to be directly determined, because it is hard to measure interface friction data. Considering that if the temperature-induced interface friction is $0 \mathrm{kN}$, then the temperatureinduced strain will be zero, therefore the monitoring strain and temperature data are used to evaluate $T_{0}$ (Ding, Wang, Hong, Song, $\mathrm{Wu}$, \& Yue, 2017). Finally, after fitting the monitoring correlation between strain and temperature, the fitting result shows that $T_{0}=7.46{ }^{\circ} \mathrm{C}$. Additionally, $f_{g}$ is calculated by loading bridge gravity on the finite element model, and $f_{g}$ is $-1670.2 \mathrm{kN}$ in the area $p_{1} p_{11} q_{11} q_{1}$ of splice plate $L$.

The bolted joint contains shear resistance capacity produced by the clamping force of friction-type high-strength bolts. However, bolt fracture weakens the shear resistance capacity, as shown in the following equation:

$$
[f]=\mu\left(N-N_{c}\right) N_{s} P,
$$

where $[f]$ - the shear resistance capacity of one splice plate, $\mathrm{kN} ; \mu-$ the static friction coefficient of contact interface, and $u=0.45 ; N$ - the number of total installed bolts; $N_{c}$ - the number of fractured bolts; $N_{s}-$ the number of contact interfaces in one splice plate; $P$ - the clamping force of bolts, and $P=355 \mathrm{kN}$. 
For the FBJHS, the total interface friction is smaller than the shear resistance capacity to ensure the safety of the bolted joint. There is one limit state when the total interface friction is equal to the shear resistance capacity, as shown in the following Eqs (3) and (4):

$$
\begin{gathered}
\left|f_{\text {total }}\right|=[f], \\
\text { or }\left|k\left(T-T_{0}\right)+f_{g}\right|=\mu\left(N-N_{c}\right) N_{s} P .
\end{gathered}
$$

Eqs (3) or (4) is the limit state equation to evaluate the safety of the bolted joint. If $\left|f_{\text {total }}\right|<[f]$, the bolted joint will be in a safe state; otherwise, the bolted joint will be in a precarious state.

\subsection{Safety evaluation result}

The limit state equation reveals the relation between the seasonal temperature $T$ and the quantity of fractured bolts $N_{c}$ regarding the safety of the bolted joint, as shown in Figure 21. The monitoring point $\left(N_{c}, T\right)$ falling into the safe zone indicates the safe state of bolted joint. In 2013, all the bolts were in good condition in the studied joint, and the maximum and minimum monitoring seasonal temperatures were $30.7{ }^{\circ} \mathrm{C}$ and $2.6^{\circ} \mathrm{C}$, respectively. So, the monitoring points $(0,30.7)$ and $(0,2.6)$ fell into the safe zone, indicated that the studied joint was in the safe state in 2013. Furthermore, the shear resistance capacity [f] of splice plate $L$ is $25560 \mathrm{kN}$, and the maximum interface friction $\left|f_{\text {total }}\right|$ in the area $p_{1} p_{11} q_{11} q_{1}$ caused by seasonal temperature and bridge gravity is $1935.3 \mathrm{kN}$, accounting for only $7.57 \%$ of the shear resistance capacity.

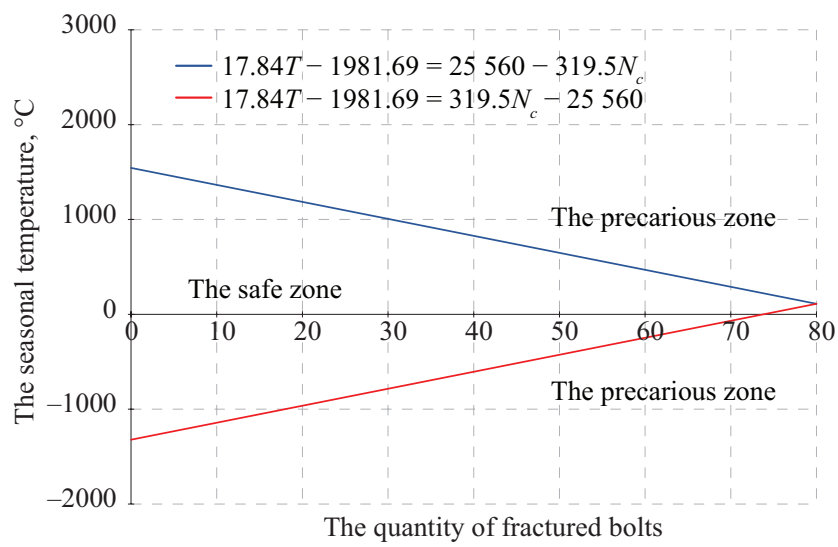

Figure 21. The relation between the seasonal temperature and the quantity of fractured bolts in the limit state Equation
Bolted Joint of Steel

Truss Bridge: Case

Study 
Therefore, an abundant safety margin exists in the splice plate $L$. Additionally, the other splice plates were also in a good state in 2013 after analysing their limit state Eqs.

\section{Conclusions}

This research primarily carried out finite element analysis on the interface friction of splice plates under conditions of seasonal temperature variation and fractured bolts, and the safety of the bolted joint was evaluated using limit state equation. The main conclusions are drawn as follows:

1. The interface pressure is mainly centred on bolt holes, and the two-layer splice plates diffuse the pressure concentration effectively. Moreover, the interface friction and seasonal temperature have similar changing trends, and their correlation shows excellent linear characteristics. The maximum and minimum interface frictions from March 2013 to November 2013 are $547.7 \mathrm{kN}$ and $47.1 \mathrm{kN}$, respectively.

2. The interface friction in the area $C_{i}$ gradually increases from $C_{1}$ to $C_{11}$, and the maximum value is $17.84 \mathrm{kN} /{ }^{\circ} \mathrm{C}$ in the area $C_{11}$. The interface friction in the area $S_{i}$ gradually decreases from $S_{1}$ to $S_{7}$ and then gradually increases from $S_{7}$ to $S_{10}$. The interface frictions caused by seasonal temperature are mainly centred in the splice plates $C, D, G, H, K, L, O$ and $P$.

3. The quantity of fractured bolts has little effect on the total interface friction and the total interface friction caused by 40 fractured bolts changes slightly from $17.84 \mathrm{kN} /{ }^{\circ} \mathrm{C}$ to $16.86 \mathrm{kN} /{ }^{\circ} \mathrm{C}$. The location of fractured bolts also has little effect on the total interface friction, and the variation of total interface friction caused by random fractured locations is between $0.61 \mathrm{kN} /{ }^{\circ} \mathrm{C}$ and $-0.44 \mathrm{kN} /{ }^{\circ} \mathrm{C}$.

4. Bolt fracture reduces the interface frictions in the bolt-fractured areas, and the reduced interface frictions in the bolt-fractured areas are transferred into the areas without bolt fracture, resulting in little change in the total interface friction.

5. The shear resistance capacity of splice plate $L$ is $25560 \mathrm{kN}$, and the maximum interface friction in the splice plate $L$ caused by seasonal temperature and bridge gravity is $1935.3 \mathrm{kN}$, accounting for only $7.57 \%$ of the shear resistance capacity. Enough safety margin exists in the friction-type high-strength bolted joint. 


\section{Acknowledgements}

The authors gratefully acknowledge the National Natural Science Foundation of China (51908545) and the Natural Science Foundation of Jiangsu Province of China (BK20180652).

\section{REFERENCES}

Bednarz III, E. T., \& Zhu, W. D. (2014). Identifying Magnitudes and Locations of Loads on Slender Beams with Welded and Bolted Joints Using Strain GaugeBased Force Transducers with Application to a Portable Army Bridge. Journal of Bridge Engineering, 19(2), 254-265. https://doi.org/10.1061/(ASCE)BE.1943-5592.0000507

Benhamena, A., Amrouche, A., Talha, A., \& Benseddiq, N. (2012). Effect of contact forces on fretting fatigue behavior of bolted plates: Numerical and experimental analysis. Tribology International, 48, 237-245.

https://doi.org/10.1016/j.triboint.2011.12.008

Ding, Y. L., Wang, G. X., Hong, Y., Song, Y. S., Wu, L. Y., \& Yue, Q. (2017). Detection and localization of degraded truss members in a steel arch bridge based on correlation between strain and temperature. Journal of Performance of Constructed Facilities, 31(5), 04017082.

https://doi.org/10.1061/(ASCE)CF.1943-5509.0001075

GB/T 1231-2006 Specifications of High Strength Bolts with Large Hexagon Head, Large Hexagon Nuts and Plain Washers for Steel Structures (in Chinese)

Jiménez-Peña, C., Talemi, R. H., Rossi, B., \& Debruyne, D. (2017). Investigations on the fretting fatigue failure mechanism of bolted joints in high strength steel subjected to different levels of pre-tension. Tribology International, 108, 128-140. https://doi.org/10.1016/j.triboint.2016.11.014

Jin, H. (2013). Discussion on Maintenance Method of Beijing-Shanghai High-Speed Railway of Nanjing Dashengguan Changjiang River Bridge, Modern Transportation Technology, 10(6), 51-55. (in Chinese)

Ju, M., \& Oh, H. (2016). Static and fatigue performance of the bolt-connected structural jointed of deep corrugated steel plate member. Advances in Structural Engineering, 19(9), 1435-1445. https://doi.org/10.1177/1369433216643894

Juoksukangas, J., Lehtovaara, A., \& Mäntylä, A. (2016). Experimental and numerical investigation of fretting fatigue behavior in bolted joints. Tribology International, 103, 440-448. https://doi.org/10.1016/j.triboint.2016.07.021

Kim, S., \& Lee, J. (2015). Blast resistant performance of bolt connections in the earth covered steel magazine. International Journal of Steel Structures, 15(2), 507-514. https://doi.org/10.1007/s13296-015-6019-0

Noh, M. H., Lee, S. Y., \& Park, K. S. (2013). Simplified Finite Element Model of an Anchor Bolt Inserted Through Concretes Considering Clamping Forces.
The Interface Friction in the Friction-Type Bolted Joint of Steel Truss Bridge: Case Study 
Journal of the Computational Structural Engineering Institute of Korea, 26(4), 293-300. https://doi.org/10.7734/COSEIK.2013.26.4.293 (in Korean)

Su, Q., Yang, G., \& Bradford, M. A. (2016). Bearing Capacity of Stud-Bolt Hybrid Shear Connection in Segmental Composite Bridge Girders. Journal of Bridge Engineering, 21(4), 06015008. https://doi.org/10.1061/(ASCE)BE.1943-5592.0000873

Wang, G. X., Ding, Y. L., Song, Y. S., Wu, L. Y., Yue, Q., \& Mao, G. H. (2015). Detection and location of the degraded bearings based on monitoring the longitudinal expansion performance of the main girder of the Dashengguan Yangtze Bridge. Journal of Performance of Constructed Facilities, 30(4), 04015074. https://doi.org/10.1061/(ASCE)CF.1943-5509.0000820

Wang, G. X., \& Ding, Y. L. (2015). Research on monitoring temperature difference from cross sections of steel truss arch girder of Dashengguan Yangtze Bridge. International Journal of Steel Structures, 15(3), 647-660. https://doi.org/10.1007/s13296-015-9011-9

Wu, T., Cao, C., Han, J., \& Ren, T. (2017). Effect of bolt rib spacing on load transfer mechanism. International Journal of Mining Science and Technology, 27(3), 431-434. https://doi.org/10.1016/j.ijmst.2017.03.009

$\mathrm{Xu}$, H. Y. (2011). Study on connection of friction-typed multiple-row high-strength bolt. Journal of Railway Engineering Society, 11(158), 67-71. (in Chinese)

Yeum, C. M., \& Dyke, S. J. (2015). Vision-based automated crack detection for bridge inspection. Computer-Aided Civil and Infrastructure Engineering, 30(10), 759-770. https://doi.org/10.1111/mice.12141

Zhang, S. B., Wang, R. H., Huang, Y. H., \& Liu, X. G. (2010). Finite Element Analysis of Mechanical Behavior of High Strength Bolt Friction Grip Long Joint. Journal of Civil, Architectural \& Environmental Engineering, 32(6), 74-79. (in Chinese)

Zhu, S. H. (2016). Maintenance suggestion and analysis on the high-strength bolt fracture of long-span steel truss bridge. Shanghai Railway Technique, 4, 79-81. (in Chinese)

Zou, X., Feng, P., \& Wang, J. (2018). Bolted shear connection of FRP-concrete hybrid beams. Journal of Composites for Construction, 22(3), 04018012. https://doi.org/10.1061/(ASCE)CC.1943-5614.0000845 